\title{
INVITATION TO AUTHORS
}

The Dalhousie Medical Journal will consider English-language abstracts and manuscripts dealing with any aspect of medicine including basic science, clinical medicine, surgery, medical education, medicolegal affairs, medical humanities, and public health. Non-health professionals conducting medically-related research are also encouraged to submit their work.

The journal will also consider for publication visual art or creative writing pieces, for which there are no specific criteria, but which are more likely to be accepted if relevant to health or medical sciences.

Please see http://ojs.library.dal.ca/DMJ for detailed manuscript requirements.

We look forward to hearing from you.

The DMJ Team

\section{CALL FOR REVIEWERS}

Are you an Expert?

All submissions to the DMJ are reviewed by professional members of the medical and scientific community. This is beneficial for the quality of the DMJ, and also contributes to valuable feedback for our manuscript authors, many of which are medical students. Our review process enables efficient communication between authors and reviewers, and provides an opportunity for students to improve their research and manuscript writing skills. Confidentiality of both reviewer and author is maintained throughout the review process.

If you are interested in becoming a reviewer please contact us at dmj@dal.ca

\section{ARTIST'S STATEMENT}

I wanted this painting to remind myself and other medical students of our potentials and strengths. As someone just starting the journey in medicine, I often feel inadequate in clinical settings. This is especially true in clerkship, where the learning curve is steep and the sheer amount of information to learn can become overwhelming. However, I think this painting serves as an important reminder for us to recognize that we often underestimate ourselves in what we know and are capable of. It helps me to recognize that all of us have deep-rooted knowledge and experiences that we bring into practicing medicine. As well, I hope this painting serves as a reminder to other medical students that they are not alone in their feelings of inadequacy. So many before us have gone through the exact same steps to become the capable physicians they are today. We are all in this journey of medicine together. 